\title{
Percutaneous periarticular analgesic injection at one day after simultaneous bilateral total knee arthroplasty: an open- label randomized control trial
}

Takuya Iseki ${ }^{1,2^{*}}$, Sachiyuki Tsukada ${ }^{1,3}$, Motohiro Wakui $^{1}$, Kenji Kurosaka ${ }^{3}$, Shinichi Yoshiya ${ }^{4}$ and Toshiya Tachibana ${ }^{2}$

\begin{abstract}
Background: The postoperative pain after total knee arthroplasty (TKA) remains a critical issue. The aim of this study was to assess the clinical effectiveness of percutaneous periarticular injection at 1 day following simultaneous bilateral TKA.

Methods: A total of 88 knees in 44 patients who underwent simultaneous bilateral TKA were randomly assigned to receive a percutaneous periarticular injection at 1 day following surgery $(n=22$ patients) or no injection ( $n=22$ patients). In the additional injection group, we injected a solution including methylprednisolone, ropivacaine, and epinephrine into the muscle belly of the vastus medialis at 1 day after surgery. In both groups, patients received an intraoperative periarticular multi-drug injection and postoperative intravenous and oral nonsteroidal anti-inflammatory drugs. The primary outcome measure was the postoperative pain at rest using a visual analog scale (VAS) and analyzed with Student's $t$ test.

Results: Compared to the no additional injection group, the additional periarticular injection group had significantly lower VAS score at 8:00 PM postoperative day 1, 6:00 AM postoperative day 2, 12:00 PM postoperative day 2, 6:00 AM postoperative day 5, 12:00 PM postoperative day 5, and 8:00 PM postoperative day 5 ( $p<0.05)$. The rate of complication did not differ between groups $(p>0.05)$.

Conclusion: Additional percutaneous periarticular injection at 1 day following TKA adding to intraoperative periarticular injection provided better postoperative pain relief.

Trial registration: Registered at the University Hospital Medical Information Network (registration number: UMIN000029759).
\end{abstract}

Keywords: Simultaneous bilateral total knee arthroplasty, Postoperative pain, Additional injection, Randomized

\footnotetext{
* Correspondence: takuyaiseki@gmail.com

'Department of Orthopaedic Surgery, Nekoyama Miyao Hospital, 14-7 Konan, Chuo-ku 950-1151, Niigata, Japan

${ }^{2}$ Department of Orthopaedic Surgery, Hyogo College of Medicine, 1-1

Mukogawa-cho, Nishinomiya, Hyogo 663-8501, Japan

Full list of author information is available at the end of the article
}

C C The Author(s). 2021 Open Access This article is licensed under a Creative Commons Attribution 4.0 International License, which permits use, sharing, adaptation, distribution and reproduction in any medium or format, as long as you give appropriate credit to the original author(s) and the source, provide a link to the Creative Commons licence, and indicate if changes were made. The images or other third party material in this article are included in the article's Creative Commons licence, unless indicated otherwise in a credit line to the material. If material is not included in the article's Creative Commons licence and your intended use is not permitted by statutory regulation or exceeds the permitted use, you will need to obtain permission directly from the copyright holder. To view a copy of this licence, visit http://creativecommons.org/licenses/by/4.0/ The Creative Commons Public Domain Dedication waiver (http://creativecommons.org/publicdomain/zero/1.0/) applies to the data made available in this article, unless otherwise stated in a credit line to the data. 


\section{Introduction}

Pain management in the early period is one of the most important factors in TKA, because the intense postoperative pain in the early period after TKA affects patient satisfaction [1-3]. Intraoperative periarticular multi-drug injection has been reported to be effective in many studies as a multimodal pain management after TKA [4-7]. In simultaneous bilateral TKA, intraoperative periarticular multi-drug injection has also been reported to be effective [8-10]. However, one of the problems with intraoperative periarticular multi-drug injection was that the pain score gradually elevated at $24 \mathrm{~h}$ postoperatively, because the effect of intraoperative periarticular multidrug injection gradually diminished $[6,11]$. The rebounding pain after the early postoperative period is a critical issue for multimodal pain management after TKA [12]. According to a previous study, the early postoperative pain score at rest after unilateral TKA was lower in patients with the additional percutaneous periarticular multi-drug injection (additional injection) [13]. The concept of this additional injection was to add the already established intraoperative periarticular multidrug injection once again at 1 day after TKA. However, there is no information of the efficacy of this additional injection for simultaneous bilateral TKA.

The purpose of this study was to examine the effects of additional injection at 1 day after simultaneous bilateral TKA. The hypothesis of this study is that the postoperative pain score would be lower in patients that received the additional injection at 1 day after simultaneous bilateral TKA.

\section{Materials and methods Study design}

This study was a prospective, single-center, two-arm, parallel-group, open-label, and randomized controlled trial. The study protocol was approved by the institutional review board. All patients provided written informed consent to participate in the study. The study was registered as a randomized controlled trial with the University Hospital Medical Information Network (registration number: UMIN000029759. Registered 30 October 2017, https://upload.umin.ac.jp/cgi-open-bin/ctr/ctr view.cgi?recptno=R000034000).

\section{Study population}

Among the patients scheduled for simultaneous bilateral TKA from November 2017 to March 2018, those who have consented to participate in this study were eligible for inclusion. The exclusion criteria were patients scheduled for unilateral TKA, staged bilateral TKA, revision TKA, TKA combined with implant removal, and patients with allergies to drugs used in the study. Patients who had poorly controlled diabetes mellitus defined as hemoglobin A1c with levels over $7.0 \%$ were also excluded because they did not receive steroids in the intraoperative periarticular multi-drug injection.
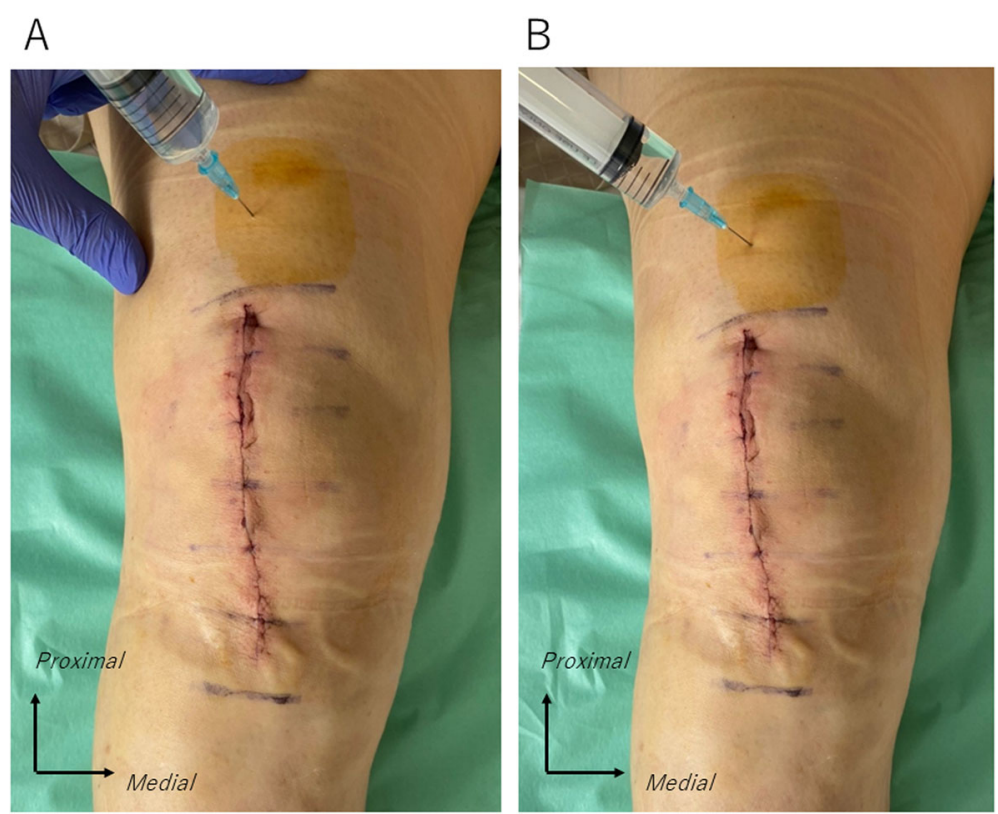

Fig. 1 Percutaneous periarticular analgesic injection at 1 day after surgery. (For right knee.) a Inject $6.1 \mathrm{ml}$ of drug solution into muscle belly of the vastus medialis just medial to the quadriceps tendon. $\mathbf{b}$ Direct the tip of the needle inward and inject $5 \mathrm{ml}$ of drug solution into the muscle belly of the vastus medialis at a more medial site than the first infiltration. 


\section{Randomization}

We randomly assigned the eligible patients to receive additional percutaneous periarticular injection at 1 day after simultaneous bilateral TKA (additional injection group) or no injection at 1 day after TKA (control group). The randomization sequence was created by permuted block randomization with a block size of 4 and a 1:1 allocation generated using computer software R, (The R Foundation for Statistical Computing). The eligible patients received a generated randomized number accordingly. Patients with even numbers were allocated to the additional injection group and those with odd numbers were allocated to the control group.

\section{Interventions}

The additional injection was routinely administered at 8 : 30 AM the day after surgery regardless of the time TKA was performed. In the additional injection group, a total of $22.2 \mathrm{~mL}$ of percutaneous periarticular multi-drug injection, including methylprednisolone $80 \mathrm{mg}[2 \mathrm{~mL}]$, ropivacaine $150 \mathrm{mg}$ [20 mL], and epinephrine $0.2 \mathrm{mg}$ [0.2 $\mathrm{mL}]$ was prepared, and divided into $11.1 \mathrm{~mL}$ and each injected into the right knee and the left knee. The additional injection technique was the same as we previously reported [13]. We percutaneously injected the analgesic solution at approximately $3 \mathrm{~cm}$ above the superior border of the antero-medial skin incision, using a 23-gauge needle (Fig. 1). First, we infiltrated $6.1 \mathrm{~mL}$ of solution into the muscle belly of the vastus medialis just medial to the quadriceps tendon (Fig. 1A). Second, we moved the needle tip and infiltrated the remaining $5 \mathrm{~mL}$ of solution into the muscle belly of vastus medialis at a more medial site than the first infiltration (Fig. 1B). After the injection of one knee, the other knee was injected in the same manner.

\section{Perioperative medication}

All patients received intraoperative periarticular injections. As an intraoperative periarticular injection, methylprednisolone 80 mg (Sol Mercort; Fuji, Toyama, Japan) [2 mL],

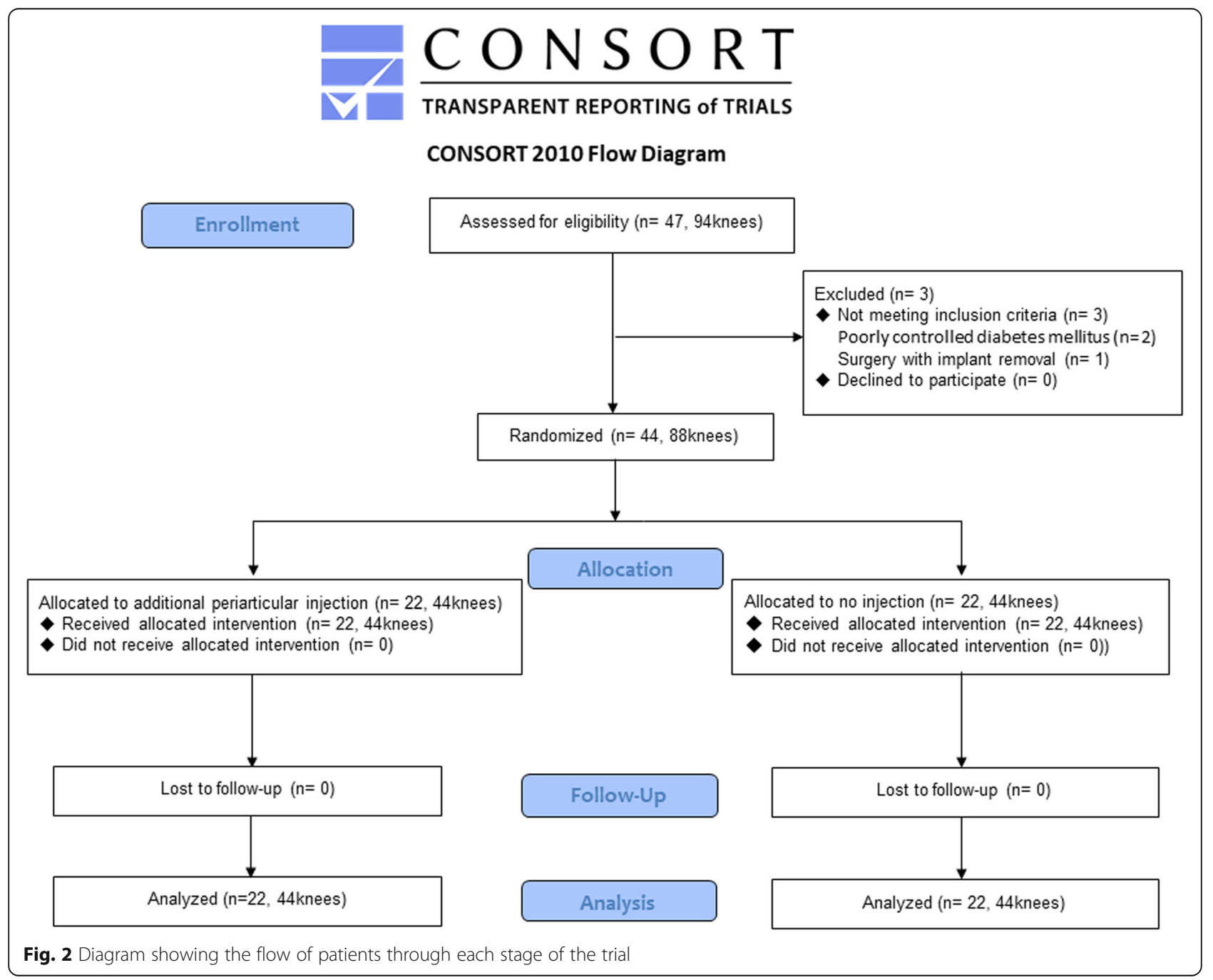


Table 1 Patient demographics and baseline clinical characteristics

\begin{tabular}{|c|c|c|c|}
\hline & Additional injection (22 patients/44 knees) & Control (22 patients/44 knees) & $P$ value \\
\hline Age (years) & $77 \pm 7$ & $76 \pm 7$ & 0.78 \\
\hline Sex (female/male) & $19 / 3$ & $15 / 7$ & 0.28 \\
\hline Height (cm) & $151 \pm 5$ & $151 \pm 9$ & 0.94 \\
\hline Weight (kg) & $59.2 \pm 9.1$ & $61.1 \pm 9.6$ & 0.50 \\
\hline $\mathrm{BMI}\left(\mathrm{kg} / \mathrm{m}^{2)}\right.$ & $25.8 \pm 3.2$ & $26.7 \pm 3.5$ & 0.34 \\
\hline Diagnosis (OA/AN) & $21 / 1$ & $22 / 0$ & 1.00 \\
\hline History of diabetes mellitus (yes/no) & $3 / 19$ & $4 / 18$ & 1.00 \\
\hline Preoperative VAS at rest $(\mathrm{mm})$ & $38 \pm 24$ & $32 \pm 26$ & 0.26 \\
\hline Preoperative VAS during activity (mm) & $46 \pm 23$ & $47 \pm 24$ & 0.86 \\
\hline Preoperative flexion angle (d) & $121 \pm 18$ & $119 \pm 15$ & 0.74 \\
\hline Preoperative extension angle (d) & $-7 \pm 6$ & $-9 \pm 7$ & 0.29 \\
\hline Surgeon (TI/ST/MW) & $11 / 8 / 3$ & $12 / 7 / 3$ & 0.95 \\
\hline Duration of surgery (month) & $159 \pm 24$ & $157 \pm 24$ & 0.80 \\
\hline
\end{tabular}

Abbreviations: $B M I$ body mass index, $O A$ osteoarthritis, $A N$ avascular necrosis, VAS visual analog scale Note: Results are expressed as means \pm standard deviation, unless stated otherwise

$7.5 \mathrm{mg} / \mathrm{mL}$ ropivacaine (Anapeine; AstraZeneca, Osaka, Japan) [40 mL], $10 \mathrm{mg} / \mathrm{mL}$ morphine hydrochloride hydrate (Takeda, Osaka, Japan) [1.0 mL], $1.0 \mathrm{mg} / \mathrm{mL}$ epinephrine (Bosmin; Daiichi-Sankyo, Tokyo, Japan) [0.6 $\mathrm{mL}$ ], $50 \mathrm{mg}$ of ketoprofen (Capisten; Kissei, Matsumoto, Japan) $[2.5 \mathrm{~mL}]$, and normal saline [13.9 mL] were routinely injected in both groups. All patients received a nonsteroidal anti-inflammatory drug $(50 \mathrm{mg}$ of flurbiprofen axetil, Ropion; Kaken, Tokyo, Japan) intravenously $1 \mathrm{~h}$ after returning to the ward, and non-steroidal antiinflammatory drug (60 mg of loxoprofen, Surinofen; Aska, Tokyo, Japan) was administered orally three times a day from 1 day after surgery. As rescue analgesic medication, a $25 \mathrm{mg}$ of diclofenac sodium suppository (Adefuroniczupo; Teva, Nagoya, Japan) was used. No narcotic pain medications were used in postoperative medication.

Table 2 Visual analog scale score of postoperative pain at rest

\begin{tabular}{|c|c|c|c|}
\hline Duration after surgery & Additional injection (22 patients/44 knees) & Control (22 patients/44 knees) & $P$ value \\
\hline Day 0 , recovery room & $1 \pm 2$ & $2 \pm 8$ & 0.12 \\
\hline Day 0, 08: 00 PM & $11 \pm 21$ & $8 \pm 13$ & 0.43 \\
\hline Day 1, 06:00 AM & $17 \pm 24$ & $7 \pm 12$ & $0.026^{a}$ \\
\hline Day 1, 12:00 PM & $18 \pm 25$ & $26 \pm 27$ & 0.16 \\
\hline Day 1, 08:00 PM & $16 \pm 21$ & $34 \pm 27$ & $<0.001^{\mathrm{a}}$ \\
\hline Day 2, 06:00 AM & $17 \pm 20$ & $39 \pm 28$ & $<0.001^{\mathrm{a}}$ \\
\hline Day 2, 12:00 PM & $19 \pm 18$ & $35 \pm 28$ & $0.0019^{a}$ \\
\hline Day 2, 08:00 PM & $21 \pm 22$ & $29 \pm 24$ & 0.13 \\
\hline Day 3, 06:00 AM & $25 \pm 27$ & $30 \pm 23$ & 0.40 \\
\hline Day 3, 12:00 PM & $21 \pm 22$ & $28 \pm 22$ & 0.18 \\
\hline Day 3, 08:00 PM & $21 \pm 22$ & $27 \pm 24$ & 0.22 \\
\hline Day 4, 06:00 AM & $21 \pm 20$ & $25 \pm 24$ & 0.39 \\
\hline Day 4, 12:00 PM & $22 \pm 19$ & $23 \pm 20$ & 0.84 \\
\hline Day 4, 08:00 PM & $16 \pm 15$ & $23 \pm 20$ & 0.068 \\
\hline Day 5, 06:00 AM & $22 \pm 20$ & $33 \pm 27$ & $0.039^{\mathrm{a}}$ \\
\hline Day 5, 12:00 PM & $17 \pm 16$ & $27 \pm 24$ & $0.020^{a}$ \\
\hline Day 5, 08:00 PM & $18 \pm 17$ & $27 \pm 25$ & $0.047^{\mathrm{a}}$ \\
\hline
\end{tabular}

Note: The additional injection was routinely performed at 08:30 AM the day after surgery regardless of the time that total knee arthroplasty was performed Results are expressed as mean \pm standard deviation, unless stated otherwise

${ }^{\text {a }}$ Significant at $p<0.05$ 


\section{Surgery and rehabilitation}

All surgical procedures were performed by one of three surgeons (IT, ST, and MW) using spinal anesthesia with 2.4 to $3.2 \mathrm{~mL}$ of $0.5 \%$ bupivacaine (Marcaine; AstraZeneca). We did not use the pneumatic tourniquet or drain for any patients. Anteromedial straight skin incision of 4 $\mathrm{cm}$ proximal to the superior patella to $1 \mathrm{~cm}$ distal to the tibial tuberosity was made, and subvastus approach were used in all surgeries. All patients received a cemented, posterior stabilized prosthesis (Scorpio NRG; Stryker Orthopedics, Mahwah, NJ, USA).

The postoperative rehabilitation regimens were the same for both groups and were started from 1 day after surgery in the afternoon.

\section{Outcome measurements}

\section{Primary outcome}

We evaluated the pain scale at rest for each knee using the VAS score as a primary outcome of this study. The VAS score ranged from $0 \mathrm{~mm}$ (indicating no pain) to
$100 \mathrm{~mm}$ (indicating extreme pain). The VAS score was measured for each knee at 12:00 PM and 8:00 PM at 1 day after surgery. From 2 to 5 days after surgery, the VAS score was measured at 6:00 AM, 12:00 PM, and 8: 00 PM. The measurements of VAS score were completed by the patient and confirmed by the nurse at all time points. In addition, we assessed whether the VAS score at rest in both groups achieved the patient acceptable symptom state (PASS) and the differences in the VAS score at rest between the two groups reached minimum clinically important difference (MCID). The threshold of PASS was defined as $33 \mathrm{~mm}$ according to the study conducted by Myles et al. [14]. The threshold of MCID was determined as $20 \mathrm{~mm}[8,11]$.

\section{Secondary outcome}

The secondary outcome of this study included the VAS score during activity, range of motion of the knee, and complications. The VAS score during activity was defined as the strongest pain experienced during physical

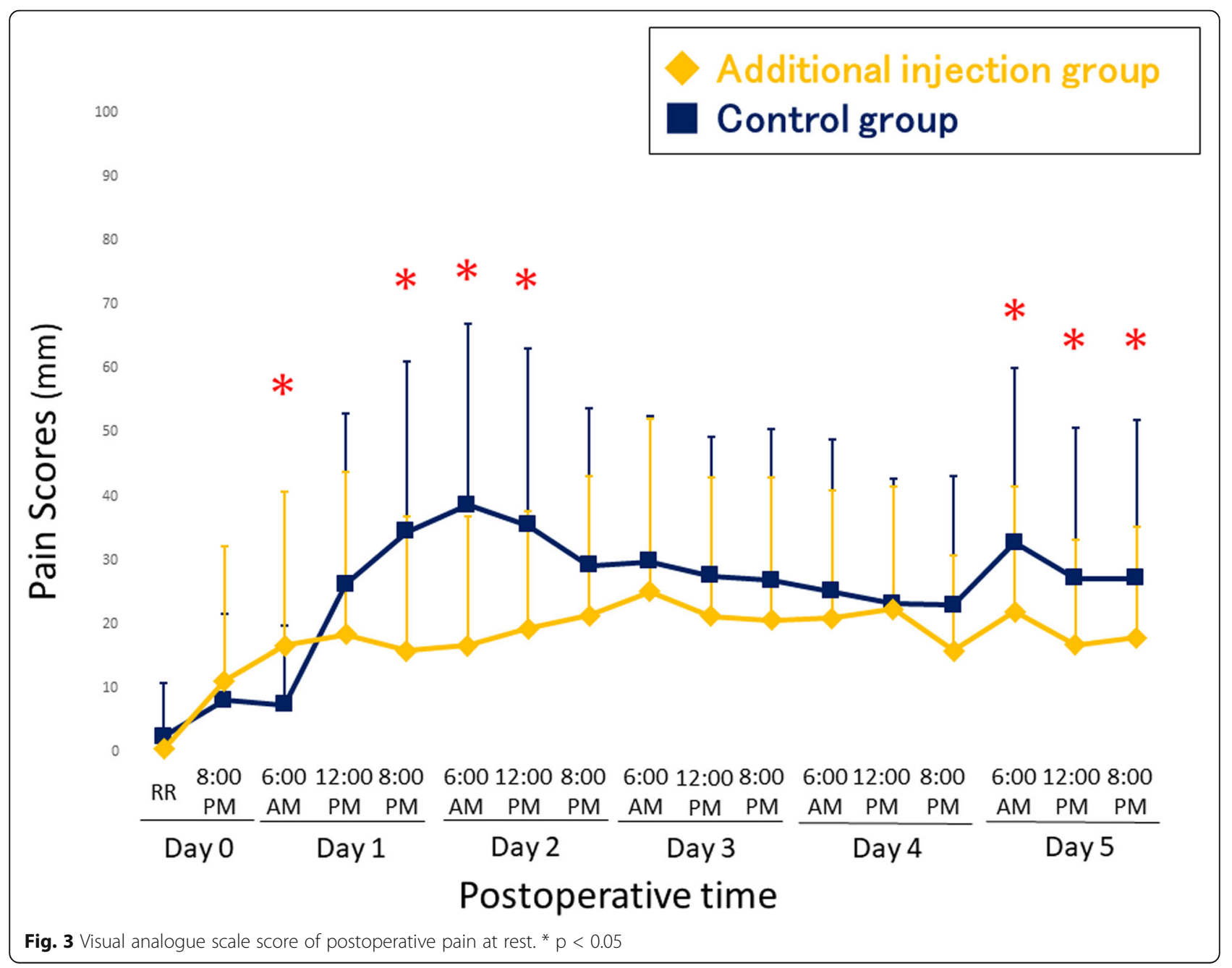




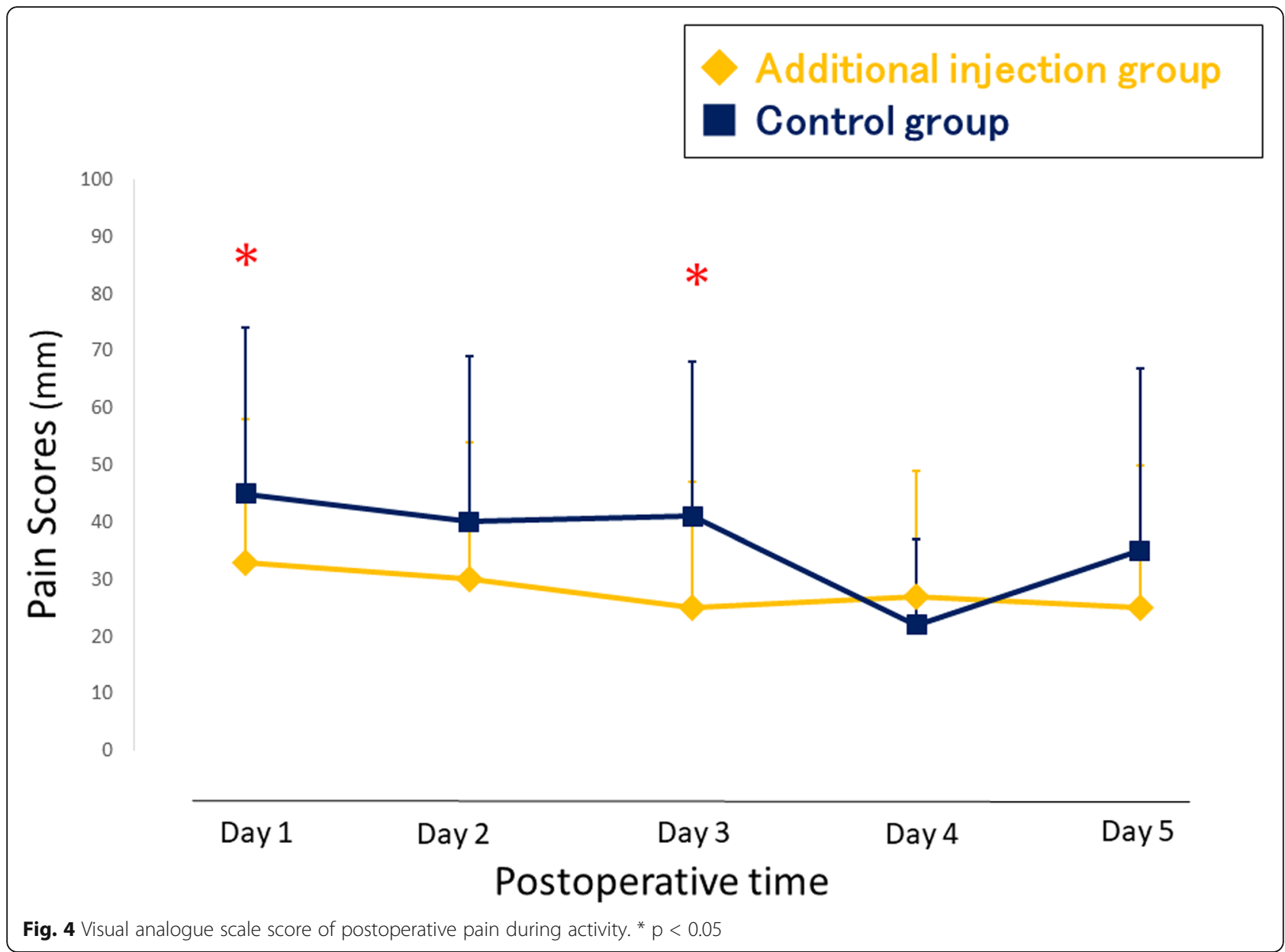

therapy. Consumption of rescue analgesia was also recorded during the study period. The data was collected from postoperative days 1 to 5 .

\section{Sample size}

As for sample size, 19 patients per group were calculated to illustrate the MCID of $20 \mathrm{~mm}$ in the VAS score at rest $[8,11]$, with a two-sided $5 \%$ significance level and $80 \%$ power. For power analysis, we used a standard deviation of $22 \mathrm{~mm}$ in the VAS score based on the results of our pilot series.

\section{Statistical analysis}

All statistical analyses were performed using $\mathrm{R}$ software. We replaced missing values of the VAS score at rest either by linear interpolation in cases where the missing values fell between two valid values or by median values from other patients at the same time point in the same treatment group. Comparisons between the study groups were performed using Student's $t$ test for continuous variables and the chisquare test for categorical variables, respectively. All tests were two-sided, and $P<0.05$ was considered statistically significant.

Table 3 Mean number of suppositories used as rescue analgesia

\begin{tabular}{llll}
\hline Duration after surgery & Additional injection (22 patients/44 knees) & Control (22 patients/44 knees) & $\boldsymbol{P}$ value \\
\hline On the night of surgery & 0 & $0.09 \pm 0.30$ & 0.16 \\
Day 1 & $0.23 \pm 0.53$ & $0.18 \pm 0.39$ & 0.75 \\
Day 2 & $0.18 \pm 0.39$ & $0.32 \pm 0.65$ & 0.40 \\
Day 3 & $0.23 \pm 0.43$ & $0.05 \pm 0.21$ & 0.082 \\
Day 4 & $0.05 \pm 0.21$ & $0.09 \pm 0.29$ & 0.56 \\
Day 5 & $0.14 \pm 0.35$ & $0.09 \pm 0.29$ & 0.64 \\
\hline
\end{tabular}




\section{Results}

\section{Participants}

The flowchart presented in Fig. 2 outlines the trial. A total of 94 knees in 47 patients underwent simultaneous bilateral TKA during the study period and 44 patients were randomly assigned to receive an additional injection ( $\mathrm{n}=$ $22)$ or no injection $(n=22)$. One patient in the additional injection group had avascular necrosis in the medial femoral condyle on both sides. Table 1 summarizes the demographic characteristics of the patients and there were no significant differences between the two groups.

\section{Primary outcome}

The pain VAS score at rest is shown in Table 2 and Fig. 3. The VAS score at 6:00 AM postoperative day 1 before the additional injection was lower in the control group. However, the additional injection group had significantly lower VAS score at 8:00 PM postoperative day 1 than the control group. Additionally, the pain VAS score at 6:00 AM postoperative day 2, and 12:00 PM postoperative day 2 were also lower in the additional injection group. The pain VAS score at 6:00 AM postoperative day 5, at 12:00 PM postoperative day 5, and 8:00 PM postoperative day 5 were also lower in the additional injection group.

In the control group, the mean pain VAS score at rest exceeded the threshold value of the PASS of $33 \mathrm{~mm}$ in the early postoperative period, at 8:00 PM postoperative day 1, at 6:00 AM postoperative day 2, and at 12:00 PM postoperative day 2. In the additional injection group, on the other hand, the mean pain VAS score at rest was below the threshold value of the PASS of $33 \mathrm{~mm}$ at all assessment time points after TKA. The difference between the two groups reached the MCID of $20 \mathrm{~mm}$ at 6 : 00 AM, postoperative day 2. The mean VAS scores at postoperative day 2, 6:00 AM were $17 \mathrm{~mm}$ in the additional injection group and $39 \mathrm{~mm}$ in the control group, respectively.

\section{Secondary outcome}

The pain VAS scores during activity are shown in Fig. 4. The additional injection group had significantly lower VAS scores at 1 day and 3 days after TKA. The consumption of diclofenac sodium suppository as rescue analgesia was similar between the two groups (Table 3).

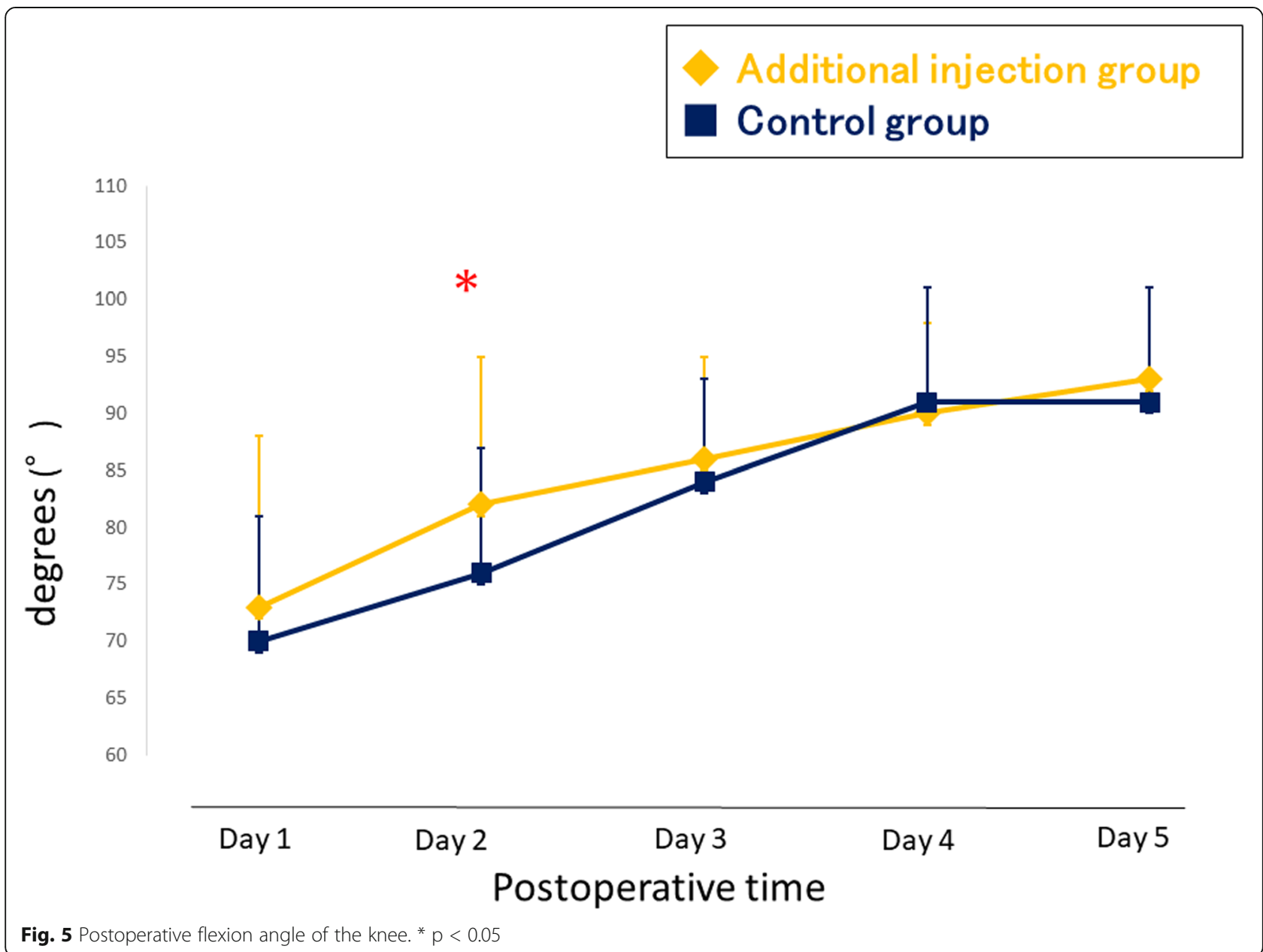


The flexion angle of the knee was better in the additional injection group at postoperative day 2 (Fig. 5). The extension angle of the knee was better in the additional injection group at postoperative day 1,3 , and 5 (Fig. 6). There were no wound complications nor surgical site infections in any study patients at the time of 2year follow-up after surgery.

\section{Discussion}

The most important finding of this study was that additional injection including methylprednisolone, ropivacaine, and epinephrine at 1 day after simultaneous bilateral TKA reduced postoperative pain score. In this study, the pain VAS scores at rest were significantly lower at 8:00 PM postoperative day 1, at 6:00 AM postoperative day 2, and at 12:00 PM postoperative day 2 in the patients who received additional injection at 1 day after simultaneous bilateral TKA. Additionally, the pain VAS scores during activity on postoperative day 1 and day 3 were also lower in the additional injection group.

Recently, some studies have reported that approximately $20 \%$ of patients are not satisfied after TKA [15-
17] and one of the causes is intense pain immediately after TKA. The early postoperative pain management is an important factor for patient satisfaction [1-3]. There are various reports on pain control in the early period after TKA. The femoral nerve block offers effective postoperative pain control [18]. However, continuous femoral nerve block causes weakness in the quadriceps muscle strength and could induce the risk of falling among other problems $[19,20]$. Ikeuchi et al. reported the efficacy of local infusion analgesia using an intraarticular catheter after TKA [21] and Meier et al. reported the efficacy of local infiltration analgesia combined with a continuous additional postoperative intraarticular perfusion [22]. However, these methods have the disadvantage of requiring catheter placement after surgery. Ali et al. reported that the use of the continuous intraarticular infusion technique increased the rate of surgical site infection [23]. In the USA, excessive postoperative opioid prescriptions have been a problem after surgery. Patients who have undergone TKA especially tend to receive the highest amount of opioid medication [24-26].

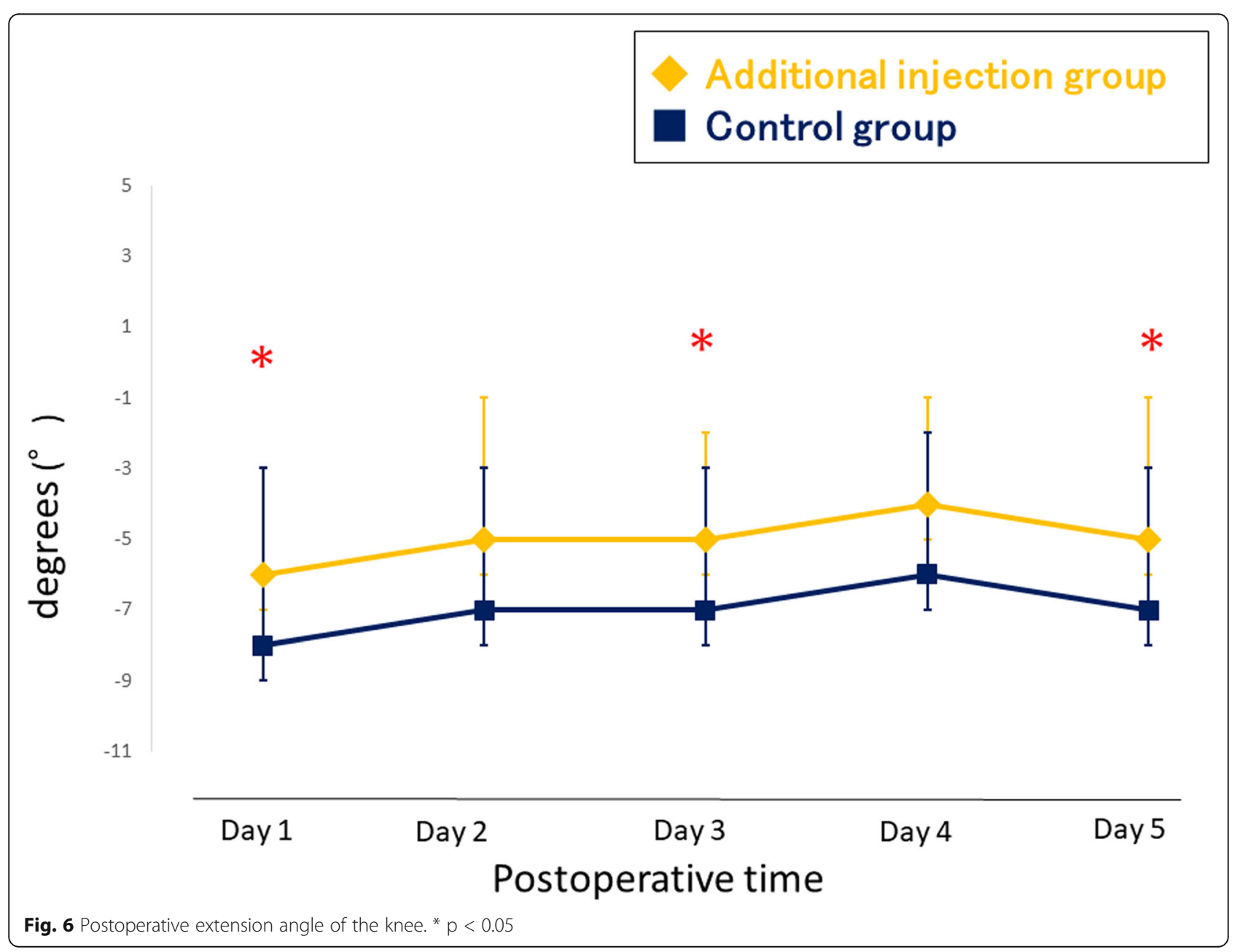


The advantages of the additional percutaneous periarticular multi-drug injection at 1 day after TKA include not requiring procedures by anesthesiologists or a replacement of a catheter. There were no wound complications nor surgical site infections in the patients who received an additional injection, which suggests that this technique might be safe and uncomplicated for the management of pain after surgery. Additionally, this technique did not require the use of opioids in our regimen. We believe that our non-opioid pain management may be an alternative regimen to the pain relief after TKA. We have investigated the efficacy of percutaneous periarticular multi-drug injection at 1 day after unilateral TKA and concluded that it was effective for early postoperative pain management [13]. In this study, the difference of the mean VAS score at rest between two groups reached the MCID of $20 \mathrm{~mm}$ only at 6:00 AM postoperative day 2. However, at 8:00 PM postoperative day 1 and at 12:00 PM postoperative day 2, the difference in the mean VAS score at rest was close to MCID of $20 \mathrm{~mm}$. We believe that it is clinically important to be able to reduce pain during this peak period of rebounding pain.

There were several limitations in this study. First, the treatment team members and patients were not blinded in this study. In addition, the control group not using placebo was also a limitation. Second, the sample size was too small to conclude the ratio of complications, including wound complications and surgical site infections, owing to their low frequency. Third, the additional injection was routinely performed at 08:30 AM postoperative day 1 , regardless of the time TKA was performed. Thus, the periods of time between the completion of TKA and the injection were not standardized among study patients. Fourth, prior to commencing RCT, we determined to use block randomization in which treatment allocation was made without regard to prior allocation. Thus, we avoided adjusting confounders using stratified randomization. Unfortunately, the mean VAS score at 6:00 AM postoperatively day 1 was significantly different between two groups. However, we believe that the block randomization is still reasonable for this RCT because it can be greatly attributable to the issue of unmeasurable confounders. Fifth, postoperative quadriceps muscle strength was not measured. Finally, we did not assess long-term patient satisfaction.

\section{Conclusion}

The additional percutaneous periarticular multi-drug injection at 1 day after simultaneous bilateral TKA may reduce early postoperative pain more effectively than no additional injection. This technique may be a new method for postoperative pain control after TKA.

\section{Abbreviations}

MCID: Minimum clinically important difference; PASS: Patient acceptable symptom state; TKA: Total knee arthroplasty; VAS: Visual analog scale

\section{Acknowledgements}

None

Authors' contributions

TI, ST, and MW performed surgeries and drafted manuscript. TI and ST developed the study design and performed formal analyses. KK managed randomizing. TT and SY supervised the study. All authors read and approved the final manuscript.

\section{Funding \\ There is no funding source.}

Availability of data and materials

The datasets used and/or analyzed during the current study are not publicly available. Data are however available from the corresponding author on reasonable request.

\section{DeclarationsEthics approval and consent to participate}

The study was initiated after receiving approval from the institutional review board of Nekoyama Miyao Hospital. All patients provided written informed consent to participate.

Consent for publication

All patients provided written informed consent to publish.

\section{Competing interests}

The authors declare that they have no competing interests.

\section{Author details}

${ }^{1}$ Department of Orthopaedic Surgery, Nekoyama Miyao Hospital, 14-7 Konan, Chuo-ku 950-1151, Niigata, Japan. ²Department of Orthopaedic Surgery, Hyogo College of Medicine, 1-1 Mukogawa-cho, Nishinomiya, Hyogo 663-8501, Japan. ${ }^{3}$ Department of Orthopaedic Surgery, Houksuikai Kinen Hospital, 3-2-1 Higashihara, Mito 310-0035, Ibaraki, Japan. ${ }^{4}$ Department of Orthopaedic Surgery, Nishinomiya Kaisei Hospital, 1-4 Ohama-cho, Nishinomiya 662-0957, Hyogo, Japan.

Received: 5 April 2021 Accepted: 23 May 2021

Published online: 01 June 2021

\section{References}

1. Lakra A, Murtaugh T, Shah RP, Cooper HJ, Geller JA. Early postoperative pain predicts 2-year functional outcome following knee arthroplasty. J Knee Surg. 2020;33(11):1132-9. https://doi.org/10.1055/s-0039-1692650.

2. Dong J, Li W, Wang Y. The effect of pregabalin on acute postoperative pain in patients undergoing total knee arthroplasty: A meta-analysis. Int J Surg. 2016;34:148-60. https://doi.org/10.1016/j.jjsu.2016.08.521.

3. Hamilton TW, Strickland LH, Pandit HG. A meta-analysis on the use of gabapentinoids for the treatment of acute postoperative pain following total knee arthroplasty. J Bone Joint Surg Am. 2016;98(16):1340-50. https:// doi.org/10.2106/JBJS.15.01202.

4. Fu P, Wu Y, Wu H, Li X, Qian Q, Zhu Y. Efficacy of intra-articular cocktail analgesic injection in total knee arthroplasty - a randomized controlled trial. Knee. 2009;16(4):280-4. https://doi.org/10.1016/j.knee.2008.12.012.

5. Vendittoli PA, Makinen $P$, Drolet $P$, Lavigne M, Fallaha M, Guertin MC, et al. A multimodal analgesia protocol for total knee arthroplasty - a randomized controlled study. J Bone Joint Surg Am. 2006;88(2):282-9. https://doi.org/1 0.2106/00004623-200602000-00005

6. Tsukada S, Wakui M, Hoshino A. Postoperative epidural analgesia compared with intraoperative periarticular injection for pain control following total knee arthroplasty under spinal anesthesia: a randomized controlled trial. J Bone Joint Surg Am. 2014;96(17):1433-8. https://doi.org/10.2106/JBJS.M.01098.

7. Busch CA, Shore BJ, Bhandari R, Ganapathy S, MacDonald SJ, Bourne RB, et al. Efficacy of periarticular multimodal drug injection in total knee. A randomized trial. J Bone Joint Surg Am. 2006;88(5):959-63.

8. Tsukada S, Wakui M, Hoshino A. Pain control after simultaneous bilatera total knee arthroplasty. A randomized controlled trial comparing 
periarticular injection and epidural analgesia. J Bone Joint Surg Am. 2015; 97(5):367-73. https://doi.org/10.2106/JBJS.N.00373.

9. Chan WWK, Chan PK, Yan CH, Henry CH, Chan CW, Chiu KY. Effect of steroid in local infiltration analgesia in one-stage bilateral total knee arthroplasty: a paired-randomized controlled study. J Knee Surg. 2020. https://doi.org/10.1 055/s-0040-1713811.

10. Laoruengthana A, Rattanaprichavej P, Mahatthanatrakul A, Tantimethanon T, Lohitnavy M, Pongpirul K. Periarticular injection of ketorolac augmenting intravenous administration of letorolac for postoperative pain control: a randomized controlled trial in simultaneous bilateral total knee arthroplasty. J Knee Surg. 2020. https://doi.org/10.1055/s-0040-1721088.

11. Tsukada S, Wakui M, Hoshino A. The impact of including corticosteroid in a periarticular injection for pain control after total knee arthroplasty: a doubleblind randomized controlled trial. Bone Joint J. 2016;98(2):194-200. https://doi.org/10.1302/0301-620X.98B2.36596.

12. Murata-Ooiwa M, Tsukada S, Wakui M. Intravenous acetaminophen in multimodal pain management for patients undergoing total knee arthroplasty: a randomized, double-blind, placebo-controlled trial. J Arthroplast. 2017:32(10):3024-8. https://doi.org/10.1016/j.arth.2017.05.013.

13. Iseki T, Tsukada S, Wakui M, Kurosaka K, Yoshiya S. Percutaneous periarticular multi-drug injection at one day after total knee arthroplasty as a component of multimodal pain management: a randomized control trial. BMC Musculoskelet Disord. 2019;20(1):61. https://doi.org/10.1186/s12891-01 9-2451-1.

14. Myles PS, Myles DB, Galagher W, Boyd D, Chew C, MacDonald N, et al. Measuring acute postoperative pain using visual analog scale: the minimal clinically important difference and patient acceptable symptom state. Br J Anaesth. 2017;118(3):424-9. https://doi.org/10.1093/bja/aew466.

15. Grosu I, Lavand'homme P, Thienpont E. Pain after arthroplasty: an unresolved issue. Knee Surg Sports Traumatol Arthrosc. 2014;22(8):1744-58. https://doi.org/10.1007/s00167-013-2750-2.

16. Scott CE, Howie CR, MacDonald D, Biant LC. Predicting dissatisfaction following total knee replacement: a prospective study of 1217 patients. J Bone Joint Surg (Br). 2010;92(9):1253-8.

17. Lavand'homme P, Thienpont E. Pain after total knee arthroplasty: a narrative review focusing on the stratification of patients at risk for persistent pain. Bone Joint J. 2015;97-B(10 Suppl A):45-8.

18. Paul JE, Arya A, Hurlburt L, Cheng J, Thabane L, Tidy A, et al. Femoral nerve block improves analgesia outcomes after total knee arthroplasty: a metaanalysis of randomized controlled trials. Anesthesiology. 2010;13(5): 1144-62.

19. Pelt CE, Anderson AW, Anderson MB, Dine CV, Peters CL. Postoperative falls after total knee arthroplasty in patients with a femoral nerve catheter: can we reduce the incidence? J Arthroplast. 2014;29(6):1154-7. https://doi.org/1 0.1016/j.arth.2014.01.006

20. Feibel RJ, Dervin GF, Kim PR, Beaule PE. Major complications associated with femoral nerve catheters for knee arthroplasty: a word of caution. J Arthroplast. 2009;24(6 Suppl):132-7. https://doi.org/10.1016/j.arth.2009.04.008.

21. Ikeuchi M, Kamimoto Y, Izumi M, Sugimura N, Takemura M, Fukunaga K, et al. Local infusion analgesia using intra-articular double lumen catheter after total knee arthroplasty: a double blinded randomized control study. Knee Surg Sports Traumatol Arthrosc. 2013;21(12):2680-4. https://doi.org/1 $0.1007 / 500167-012-2004-8$

22. Meier M, Sommer S, Huth J, Benignus C, Thienpont E, Beckmann J, et al. Local infiltration analgesia with additional intraarticular catheter provide better pain relief compared to single-shot local infiltration analgesia in TKA. Arch Orthop Trauma Surg. 2021;141(1):105-11. https://doi.org/10.1007/s004 02-020-03606-0.

23. Ali A, Sundberg M, Hansson U, Malmvik J, Flivik G. Doubtful effect of continuous intraarticular analgesia after total knee arthroplasty: a randomized double-blind study of 200 patients. Acta Orthop. 2015;86(3): 373-7. https://doi.org/10.3109/17453674.2014.991629.

24. Blendon RJ, Benson JM. The public and the opioid-abuse epidemic. N Engl J Med. 2018;378(5):407-11. https://doi.org/10.1056/NEJMp1714529.

25. Sabatino MJ, Kunkel ST, Ramkumar DB, Keeney BJ, Jevsevar DS. Excess opioid medication and variation in prescribing patterns following common orthopaedic procedures. J Bone Joint Surg Am. 2018;100(3):180-8. https:// doi.org/10.2106/JBJS.17.00672.

26. Manchikanti L, Helm S II, Fellows B, Janata JW, Pampati V, Grider JS, et al. Opioid epidemic in the United States. Pain Physician. 2012;15(3 Suppl):ES9-38.

\section{Publisher's Note}

Springer Nature remains neutral with regard to jurisdictional claims in published maps and institutional affiliations.
Ready to submit your research? Choose BMC and benefit from:

- fast, convenient online submission

- thorough peer review by experienced researchers in your field

- rapid publication on acceptance

- support for research data, including large and complex data types

- gold Open Access which fosters wider collaboration and increased citations

- maximum visibility for your research: over $100 \mathrm{M}$ website views per year

At BMC, research is always in progress.

Learn more biomedcentral.com/submissions 